\title{
KEY PERFORMANCE INDICATORS FOR TURBOELECTRIC DISTRIBUTED PROPULSION
}

\begin{abstract}
Purpose - Recent advancements in electrified transportation have been necessitated by the need to reduce environmentally harmful emissions. Accordingly, several aviation organisations and governments have introduced stringent emissions reduction targets for 2050. One of the most promising technologies proposed for achieving these targets is turboelectric distributed propulsion (TeDP). The objective of this study was to explore and identify key indicators for enhancing the applicability of TeDP in air transportation.

Methodology - An enhancement valuation method was proposed to overcome the challenges associated with TeDP in terms of technological, economic, and environmental impacts. The result indicators (RIs) were determined; the associated performance indicators (PIs) were analysed; and the key RIs and PIs for TeDP were identified. Quantitative measurements were acquired from a simulated TeDP case study model to estimate the established key PIs.

Findings - It was determined that real-world TeDP efficiency could be enhanced by up to $8 \%$ by optimising the identified key PIs.

Originality - This study is the first to identify the key PIs of TeDP and to include a technoeconomic environmental risk analysis based on the identified key PIs. The findings could guide developers and researchers towards potential focus areas to realise the adoption of TeDP.
\end{abstract}

Keywords: Turboelectric power, Key performance indicator, Transport propulsion, Environmentally harmful emission, Techno-economic impact

Article classification: Research paper.

\section{Introduction}

Environmental protection has been identified as a leading objective for the aeronautical industry over the next 30 years and beyond. Accordingly, the Advisory Council for Aeronautics Research in Europe (ACARE) established the 2050 flightpath vision to develop technologies 
and revolutionary ideas that can reduce greenhouse gas (GHG) emissions (Darecki et al., 2011). The target is to reduce $\mathrm{CO}_{2}$ emissions per passenger per kilometre by $75 \%$, NOx by $90 \%$, and acoustic noise by $65 \%$. Furthermore, aircraft movement on the ground should produce zero emissions (Clegg, 1999; Darecki et al., 2011). This ambitious emission reduction strategy is not limited to Europe; it has been universally adopted as a requirement for the International Air Transport Association (IATA) and the International Civil Aviation Organization (ICAO) (IATA, 2016; ICAO, 2013).

To achieve the aforementioned objectives, alternative solutions for aircraft power and propulsion technologies need to be investigated and integrated into existing aircraft systems. Among existing methods and technologies supporting the electrification of propulsion systems, turboelectric distributed propulsion (TeDP) has been identified as a well-suited propulsion electrification system that combines mechanical and electrical advantages. The main challenges faced by any electrical system are its energy conservation parameters and electric feed requirements, and the optimisation of such a system requires the balancing of interrelated benefits and drawbacks. The concept of risk analysis can thus be used to balance the weight, energy life cycle, capacity, size, and cost drawbacks inherent in the design of electrical propulsion systems.

The powertrains of TeDP systems comprised electric generators and motors that convert mechanical energy to electricity and vice versa; a transmission, which is typically a system of gears that can adjust the rotation and power via gear ratios; and other electrical components, such as rectifiers and cryocoolers. Electric generators in a turbine, whether a gas or steam turbine, convert mechanical energy to electrical energy, while electric motors convert electricity to mechanical energy to power drive shafts. Although such a system appears simple, several critical factors must be considered, particularly during the design stage, to meet the performance goals of future air traffic and aircraft systems. Accordingly, the design of such TeDP systems must be highly integrated (National Academies of Sciences, 2016; Wick et al., 2015).

Similar to other means of mass transportation, commercial aviation emits $\mathrm{CO}_{2}$ into the atmosphere. By 2016, $\mathrm{CO}_{2}$ emissions from the aviation industry constituted approximately 2.0$2.5 \%$ of the overall annual global $\mathrm{CO}_{2}$ emissions (Lee et al., 2009; National Academies of Sciences, 2016). In the United States, the aviation industry accounted for approximately $23 \%$ of the national annual $\mathrm{CO}_{2}$ emissions (Graver et al., 2019). As the commercial aviation sector 
continues to grow, particularly in terms of cargo ton-miles and revenue-passenger miles, the corresponding emissions will also continue to increase. Research has indicated that over $90 \%$ of emissions from the aviation industry originate from large aircraft (i.e., aeroplanes with at least 100 passengers, or single- and twin-aisle aeroplanes). Therefore, research teams and agencies focusing on air-transportation technology must consider environmental factors and explore methods of redesigning propulsion systems to improve their efficiency. Based on the effects of aircraft size on GHG emissions, technologies for larger aircraft should receive more attention.

Previous research has outlined the notable system-wide challenges associated with reducing the aviation industry's $\mathrm{CO}_{2}$ emissions. Most of these challenges are associated with policies and economic factors. Considering the scope of this present study (a TeDP system), the relevant challenges are related to the complex nature of aircraft systems. Most commercial aircraft consist of numerous distinct, judiciously integrated systems that are carefully controlled to guarantee their safety and performance. Therefore, the introduction of next-generation technologies requires meticulous system integration to ensure that the functionality of any one system, or even that of the aircraft as a whole, is not adversely impacted by improvements made to another system. Consequently, incorporating novel aircraft propulsion technologies into an operational aircraft is an intricate engineering task. For instance, all essential electrical components (i.e., generators, motors, and electrical distribution systems) in a TeDP system are associated with the generation of considerable heat. Therefore, a robust thermal system must be implemented to dissipate this heat effectively, and the weight and power requirements of this system would likely affect the performance of the aircraft. Additionally, during the development of any new aircraft system, comprehensive certification procedures need to be followed, as safety is a critical aspect of aviation that must always be guaranteed (National Academies of Sciences, 2016).

Several public and private organisations are developing policies, standards, and novel technologies to create an efficient turboelectric system that will significantly reduce carbon emissions. Such endeavours could also improve the economic performance of aviation systems, as cargo and passengers could be transported over the same distances while consuming less fuel (National Academies of Sciences, 2016). In the U.S., these organisations include the U.S. Departments of Energy, Defence, Commerce, and Agriculture; the U.S. 
Environmental Protection Agency; the U.S. Federal Aviation Administration; the U.S. National Aeronautics and Space Administration; academia; and engine and aircraft manufacturers.

The introduction of electrical components provides unparalleled flexibility to TeDP systems, and fan propulsors coupled with power-generating turbines have been particularly effective. This flexibility has enabled reductions in fuel burn, noise, and emissions (Jansen et al., 2015a). However, the introduction of such electrical components comes at the cost of increased weight and occasionally impacts the overall efficiency of the propulsion system, potentially outweighing its benefits. Therefore, risk analysis is required to assess the performance of the TeDP electrical power system to ensure a net benefit at the level at which it is deployed. Several key indicators, such as functional or performance parameters, must be defined, and four related levels of these indicators must be analysed to ensure a successful break-even analysis. Accordingly, the objective of this research is to define the key performance indicators (KPIs) of a TeDP system application, which requires the identification of result indicators (RIs), performance indicators (PIs), and key result indicators (KRIs) (Parmenter, 2010). The KPIs defined here are quantifiable measurements applied to evaluate whether the TeDP system meets the objective performance requirements, whereas RIs are the assessment parameters for determining the PIs. Figure 1 presents the general relationships between KPIs and the other indicators.

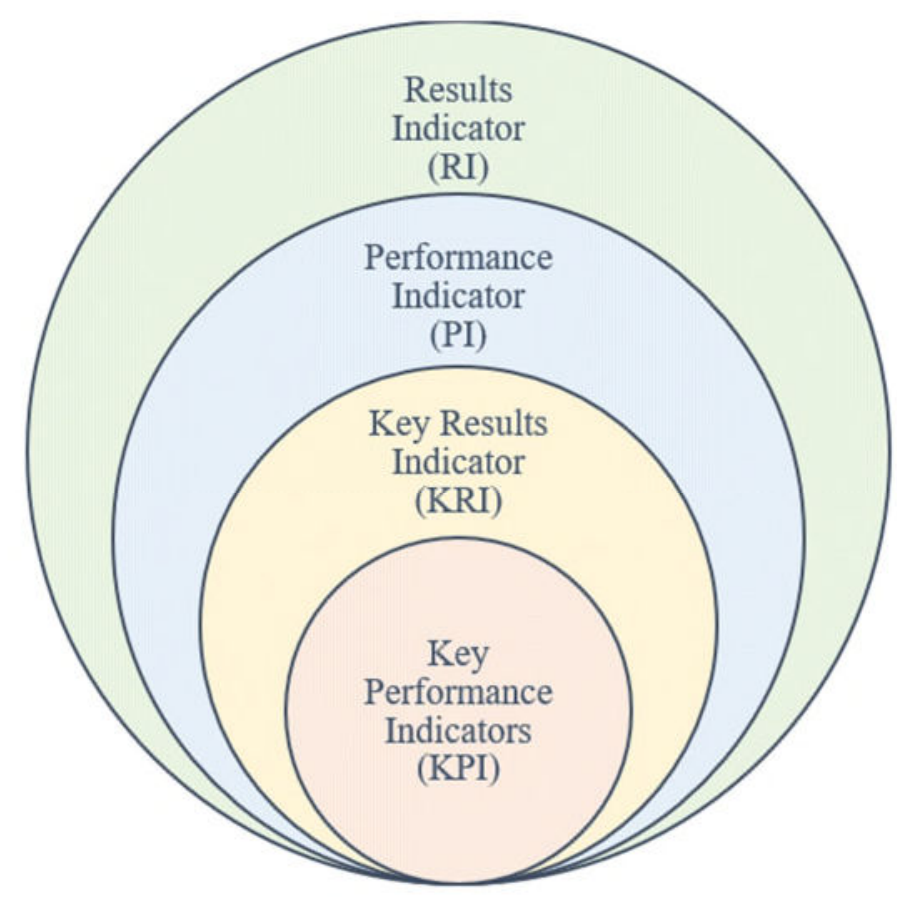

Figure 1: Hierarchy of indicators 
Performance management is an important requirement for ensuring the success of TeDP systems in the aviation industry. The implementation of TeDP systems will be evaluated through the KPI method until the target objectives are achieved. KPIs are linked to management via system efficiency improvements in the three stages of the system life cycle: design and model, manufacturing, and maintenance. For example, smart KPI frameworks have the capability of reducing wasted costs and power as much as possible while strengthening productivity, using a mainstream management field (Adams and Frost, 2008; Ishak et al., 2019). Measuring KPIs sustainably means using them to determine the effectiveness of a TeDP system in technical, economic, and environmental terms, which can help designers and engineers, as well as individuals at the highest managerial levels. To explain this concept further, we consider the three levels of applied KPIs in a power-generation project — the project execution level, project management level, and decision-making level (Zhao et al., 2017). Figure 2 illustrates the relation between these three levels. The first level can identify the engineering indicators in the project, while the second level is responsible for assessing the economic costs, quality, and environmental risks. The decision-making level is the overall management required to leverage the project by utilising the KPI-based results and recommendations.

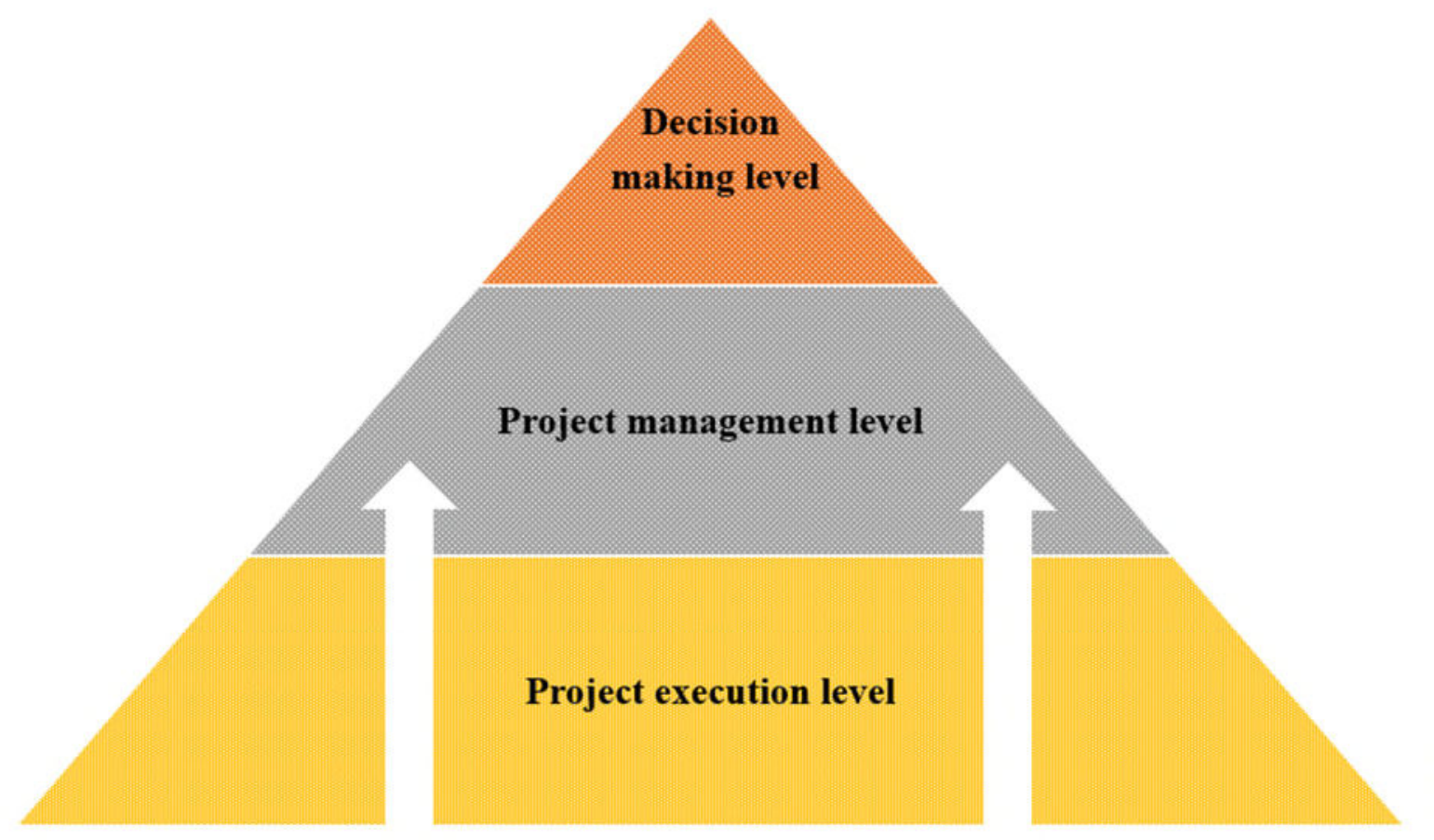

Figure 2: TeDP system project managerial pyramid 
Therefore, this study comprehensively investigates some of the key techno-economic and environmental parameters as well as the related PIs of a TeDP system. After outlining the $\mathrm{CO}_{2}$ emissions from commercial aviation, a TeDP system configuration is evaluated to assess its emission-reducing capabilities, as well as the complexities associated with its design and integration into existing aircraft systems. Additionally, some of the basic considerations in terms of aircraft-propulsion integration and technological needs are discussed, and the KRIs and their associated performance parameters and indicators are presented. As the objective of this study is to establish an approach for minimising global GHG emissions from commercial aviation, the effects of all energy and propulsion technological components in a TeDP system, from energy storage devices (such as batteries, alternative fuels, or jet fuel) to propulsion power generation components (such as motors or gas turbines or both), on aircraft performance are considered in this evaluation.

The practical and societal implications of this study lie in defining the knowledge gaps that TeDP needs to fill through research and techno-economical assessments. Moreover, the findings are expected to encourage societies to focus on future aviation developments that can lead to better solutions regarding GHG emissions and achieve green and robust transportation systems. The results of this research complement previous work done on practical TeDP applications.

The remainder of this paper is structured as follows. First, the RIs of the TeDP system are explained, and their implementation is discussed. Next, the PIs of the TeDP system are introduced. Then, the RIs that have the most significant effect on the technical, economical, and environmental performance of the TeDP system are identified. The same aspects are then investigated in terms of KRI outcomes to obtain the required KPIs. Quantitative measurements of each KPI outcome are then conducted using simulations to estimate their value and potential contribution to the TeDP performance improvement, using a risk analysis methodology. Finally, recommendations and conclusions are provided for integrating the TeDP system and addressing existing limitations through future research.

\section{Productivity and Performance Management}

In light of the implementation of new systems such as TeDP, productivity and performance management are needed to transform proposed designs into real systems. Moreover, assessing the maximisation of long-term performance and overcoming productivity challenges as a problem-solving method (Irfani et al., 2019) is one of the goals of this project. This study aims 
to support the production system, from manufacturing to operation and maintenance. In general, KPIs act as a measurement tool in the application of strategies and goals in intelligent systems (Lundgren et al., 2020; Manoochehri, 1999; Shahin and Mahbod, 2007).

The performance management process requires data for analysis and measurement, especially for proposed systems, to establish real data that could be customised by following the hierarchy of determining the indicators. This area of research is limited in terms of exploring the indicators and measurement tools (Halachmi, 2011; Singh and Sushil, 2013). In the following sections, these indicators are determined and discussed in detail for TeDP systems.

\section{Result indicators}

The design of a TeDP system, or any other electric propulsion system, must meet the expectations of all the stakeholders of an aircraft, including customers, owners, environmental agencies, and governments. The expectations of these groups regarding such technologies are outlined in this section as the RIs of turboelectric systems. These RIs can be classified into technical, environmental, and economic indicators, as illustrated in Figure 3.

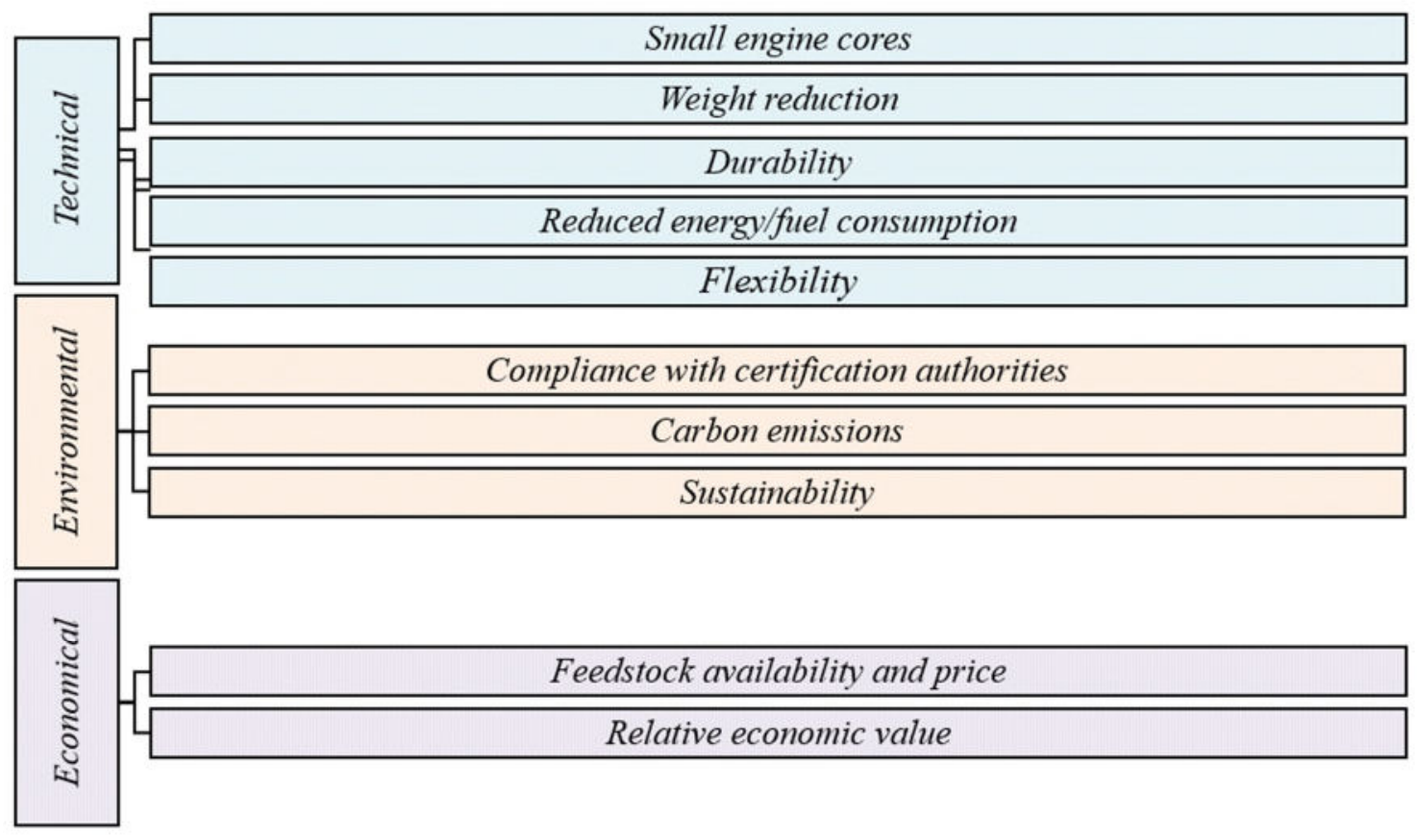

Figure 3: TeDP system results indicators

The nine indicators suggested in the literature (Alrashed, Nikolaidis, Pilidis and Jafari, 2020; Alrashed, Nikolaidis, Pilidis, Alrashed, et al., 2020; Choi et al., 2014; Davies et al., 2013, 2014; Liu, 2013; Liu et al., 2016; Nalianda and Singh, 2014; Schiltgen et al., 2013, 2016; Shaw 
et al., 2014) for analysing the total efficiency of a TeDP system are shown in Fig. 2. These indicators were categorised and analysed in this study based on the techno-economic environmental risk analysis (TERA) methodology (Doulgeris et al., 2012; Gargalo et al., 2016; Goldberg, 2017; Nathan and Scobell, 2012). This methodology is applied in three steps: problem definition, data collection, and risk analysis. Each part of the TERA is described in terms of its indicators in the following sections.

\subsection{Technical indicators}

These indicators consist of technical data obtained after defining the problem represented by each indicator and performing risk analysis.

\subsubsection{Small engine cores}

The performance of an engine core is primarily assessed by a certification agency, and the size of the engine core is intimately related to the overall system performance (Chapman, 2019; Felder et al., 2009a; Kim et al., 2013). In this case, the engine cores of a TeDP system must be relatively small to avoid weight and size problems, which are likely to impact the efficiency of the system. However, considerable care must be taken to ensure that efforts to reduce core sizes do not cause a decline in performance factors, such as aircraft efficiency (Brown, 2011a).

\subsubsection{Weight reduction}

The materials for the components of a TeDP system must be selected suitably to ensure that the resulting design weighs less than the previous design, to accommodate the components of the aircraft and realise any associated benefits (English et al., 1959; Kim et al., 2013; Nathan and Scobell, 2012; Salyer, 2009). The total weight of a turboelectric propulsion system includes the weights of seven elements: the gas turbine engine, electric generator, superconducting bus, cryogenic inverter, motors, propulsive fans, and cryocooler. One of the heaviest elements of the electric system is the electric generator, whose weight is estimated to be the hundreds of kilograms (Oberly, 2006). A combined gas turbine and generator can weigh as much as 16300 $\mathrm{kg}$, assuming $7461 \mathrm{~kg}$ per gas turbine in a twin-engine and generator aircraft (Tong et al., 2004).

\subsubsection{System component durability}

It is difficult to maintain efficient fuel conversion when parts of any propulsion system age rapidly. Therefore, research must be conducted to find materials that do not age rapidly and to 
develop methods of fabricating components in a manner that imparts anti-ageing properties to the components (Esker, 2018; Hofer, 2012; Kohlman, 2017; Misra, 2018).

\subsubsection{Reduced energy/fuel consumption}

Every aircraft owner/operator would prefer their aircraft to be less expensive to operate and maintain, and fuel consumption accounts for a major portion of operation costs (Felder, 2014; Kim et al., 2008a; Liu et al., 2013). Therefore, TeDP systems must be designed for efficiency and minimal fuel consumption.

\subsubsection{Flexibility}

Turboelectric systems have flexibility in terms of integration, depending on aircraft size and power delivery, which include the electric configuration and vehicle architecture (Brown, 2011b; Felder et al., 2009b). Furthermore, flexibility could customise the system weight and reduce costs based on the available technologies and regulations (Felder, Brown, et al., 2011; Jansen et al., 2015b, 2017a; Kim et al., 2008b; Masson et al., 2013).

\subsection{Environmental indicators}

These indicators represent the environmental data obtained after defining the problem represented by each indicator and weighting it for risk analysis.

\subsubsection{Compliance with certification authorities}

The safety of an aircraft with respect to the environment is a critical factor. Therefore, the design of all aircraft components must be subjected to a thorough assessment as well as testretest procedures to ensure optimal performance. Accordingly, one of the most critical RIs is compliance with all environmental certification authorities. Some agencies tasked with these certification tests include the U.K. Civil Aviation Authority, the U.S. Federal Aviation Administration, and the European Aviation Safety Agency (Brelje and Martins, 2019a; Kim et al., 2014; Kim et al., 2008). Therefore, any turboelectric technology must be subjected to scrutiny by experts from these agencies to ensure that it fully conforms to requirements regarding all operational aspects of the aircraft.

\subsubsection{Carbon emissions}

As outlined in Section 1, in 2016, the commercial aviation industry contributed over $2 \%$ of overall annual global $\mathrm{CO}_{2}$ emissions. As the impacts of these emissions are experienced globally, every aircraft system or component, particularly those involved in propulsion, must 
be improved to reduce this percentage. Climate change has been an increasingly severe outcome of GHG emissions and has already impacted global economic, social, and ecological systems. Accordingly, many environmental agencies have developed extensive programs to reduce carbon emissions using financial incentives. Therefore, the reduction of carbon emissions represents a critical RI of TeDP systems as it will directly impact the financial viability of turboelectric propulsion technology in an emission reduction-oriented market (Brelje and Martins, 2019b; Nalianda and Singh, 2014; Schäfer et al., 2016; Zeng et al., 2020).

\subsubsection{Sustainability}

Sustainability is one of the critical environmental factors that can determine the economic viability of a turboelectric propulsion system (Kim et al., 2014; Łukasik, 2017; Luongo et al., 2009; Yazar, 2019). Although there is currently a focus on developing alternative jet fuels, the sustainability of the sources of these alternative fuels must be considered (Daffey, 2014). Therefore, any impact associated with the utilisation of an alternative fuel source, such as environmental and economic effects, should be explored in a feasibility study of sustainable alternative jet fuels (SAJFs). In most cases, government incentives are required to make such ventures profitable (Bann et al., 2017). When an alternative fuel can be utilised for a long time with little or no impact, it can be considered sustainable.

\subsection{Economic indicators}

These indicators represent the economic data obtained after defining the problem represented by each indicator and weighting it for risk analysis.

\subsubsection{Fuel availability and price}

From an economic perspective, fuel must not only be sustainable but also cost-effective. It has already been demonstrated that SAJFs can be developed in the form of drop-in fuels through several processes (National Academies of Sciences, 2016). However, these processes are technically challenging, and overcoming the challenges would ensure the economic competitiveness of SAJFs produced on a large scale. This is a crucial RI of a TeDP system, as system operation using a low-cost fuel would significantly reduce operational costs (AlNuaimi et al., 2020; DiNovo, 1978; Dryer, 2014; Propulsion et al., 2016). As such, this RI affects the operational outcomes of the entire system. 


\subsubsection{Relative economic value}

The proposed TeDP system must offer considerable relative economic value. A balanced technological portfolio is required when designing TeDP systems to ensure that any type of economic uncertainty associated with changes in economic factors, such as fuel prices, would not negatively affect the sustained decrease in emissions achieved by the industry (Goldberg et al., 2017; National Academies of Sciences, 2016).

\section{Performance indicators}

As mentioned in Section 1, electrical propulsion systems consist of main components such as electrical distribution systems, generators, and motors. These components are the focus of electrical propulsion research. This section outlines several critical PIs associated with achieving the desired RIs outlined in Section 3. Figure 4 illustrates the technical, economic, and environmental PIs used to conduct the TERA for the TeDP system; these PIs are discussed in the following sections.

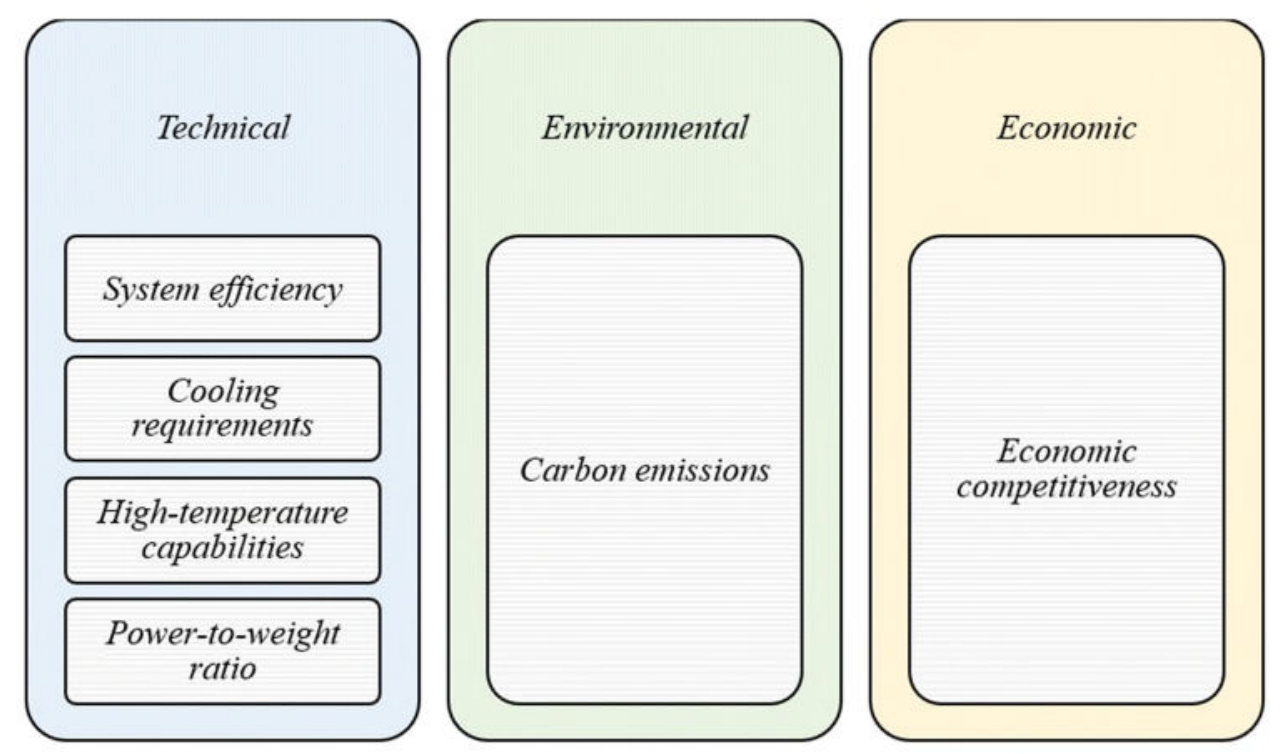

Figure 4: TeDP system performance indicators

\subsection{Technical indicators}

\subsubsection{System efficiency}

One of the most important PIs of any system is its efficiency, particularly from the perspective of performance. Ensuring efficiency is one of the main objectives of any new technology intended for use in TeDP systems. Two main types of efficiency are desirable in any propulsion system. The first is the propulsive efficiency of the system, which is the propulsive power as a function of the generation rate of propulsive, kinetic energy (Jansen et al., 2015a, 2017b). In 
other words, propulsive efficiency is the efficiency of fuel conversion into the kinetic energy required to propel the aircraft after offsetting any losses due to gravity or aerodynamic drag (Stoll et al., 2014), or the fraction of mechanical energy actually utilised to propel the aircraft. The propulsive efficiency of a TeDP system can be enhanced by boundary layer ingestion, which ensures that a lower velocity flow is ingested by the system's propulsor near the airframe, leading to the re-energisation of the wake and significantly decreasing the drag (Jansen et al., 2015a; Uranga et al., 2014). The second aspect of efficiency is the thermodynamic performance of the propulsion system, which is the quantity of work output as a function of the heat generated by the system. In the TeDP system of an aircraft, this type of efficiency is related to the materials selected in the design of the system components (Brown, 2011a).

\subsubsection{Cooling requirements}

A TeDP system converts energy from one form to another. Hence, it will generate immense amounts of heat. Therefore, it is important to ensure that the required cooling systems are as straightforward as possible while still efficiently executing the desired function. The cost of the required cooling mechanism must be reduced without impacting any of the functionalities of the system as a whole. Thus, a TeDP system must execute its propulsion functions without requiring any additional complex heat-dissipation systems. Accordingly, the cooling requirements of the TeDP system constitute a critical PI (Armstrong et al., 2012; Carre et al., 1985; Felder et al., 2009a; Felder, Kim, et al., 2011).

\subsubsection{High-temperature capabilities}

As mentioned for the previous indicator, due to the considerable heat generated by a TeDP system, all the system components and their materials must be able to perform their functions accurately and precisely under high temperatures (Armstrong et al., 2013, 2012). Accordingly, research must be conducted to develop measures to ensure that the performance of the TeDP system and its components is not negatively impacted by high temperature.

\subsubsection{Power-to-weight ratio}

The power-to-weight ratio PI is determined by the materials selected when designing the TeDP system and is calculated by multiplying the velocity of the aircraft by its thrust per unit mass. The power-to-weight ratio is a suitable measure of the effectiveness of a propulsion system as a whole (Bann et al., 2017). 


\subsection{Environmental indicators: Carbon emissions}

In addition to being a critical PI of interest for environmental agencies, carbon emissions can serve as an indicator of how effectively the TeDP system performs its propulsion function. This PI can be improved using numerous methods, including a careful material selection process which ensures that thorough research and test-retest procedures are performed on potential materials such that only the most suitable are utilised. This may involve materials that do not undergo significant reactions leading to $\mathrm{CO}_{2}$ emissions, or materials that will have a smaller impact on the overall weight of the resulting TeDP system. Reduced weight, and hence reduced drag, reduces the energy required to fly an aircraft. Other possible approaches for reducing $\mathrm{CO}_{2}$ emissions include propulsion system efficiency enhancements (i.e., improving the conversion of fuel into thrust) and reduction of the carbon intensity of the required energy by decreasing carbon emissions from electricity sources such as generators and batteries (Graham et al., 2014).

\subsection{Economic indicators/competitiveness}

Commercial aviation is one of the most competitive industries in the world. One of the key drivers of competition is the quest for fuel-burn reduction, which also directly impacts $\mathrm{CO}_{2}$ emissions (National Academies of Sciences, 2016). Cost is fundamental in the development of a TeDP system as it directly affects the economics associated with purchasing and operating an aircraft. Therefore, the overall impact of a particular TeDP system design on the economic competitiveness of an aircraft is a crucial consideration. Designers must be able to illustrate how the proposed design will be economically competitive with existing designs. Therefore, economic competitiveness can be considered a PI until the new system helps the aircraft gain a competitive advantage in the industry.

\section{Key results indicators}

Section 3 detailed measurements of TeDP system results in the form of RIs. In this section, the KRIs associated with those indicators for a turboelectric aircraft, such as reliability, redundancy, independent power, and speed control, are highlighted.

In terms of reliability and redundancy requirements, a TeDP system must meet the safety standards currently met by contemporary aircrafts. The primary standard is the fail-safe requirement, in which catastrophic effects are never allowed to occur due to any given singlepoint failure at the aircraft level. Furthermore, the degrees of oversizing and redundancy 
required to provide support for safety- and flight-critical loads during off-nominal failure cases determine the overall maximum, volume, and weight capacities of airborne power systems (Jansen et al., 2015a).

In terms of power and speed control, several electric aircraft-drive configurations can provide independent power and speed control for each fan propulsor. This enables critical configurations that are almost impossible to achieve in older aircraft. Such configurations include noise-minimisation strategies, the ability to provide high-velocity wing blowing with a regulated thrust, the regulation of yaw via differential thrust, flight regimes that optimise operation, and decoupling of the turbine and fan speeds.

\section{Key performance indicators}

This section highlights the main actions and activities that are crucial to the success of TeDP systems and are accordingly identified as KPIs. Overall, the KPIs for any TeDP system can be described in terms of system efficiency, energy consumption, and design masses (Verbano and Crema, 2015; Zamboni et al., 2019). As stated in Section 4, system efficiency is the ratio of the input power and output power of a system. In this case, overall efficiency can be considered in terms of the system's thermodynamic performance and propulsive efficiency, as discussed in Section 4. In terms of the energy consumption of the electric drive of a TeDP system, the two key performance parameters are electrical efficiency (usually denoted as $\eta_{E D}$ ) and specific power (denoted as $S p_{E D}$ ), which is defined as the ratio of the overall mass of the system and its rated power. Figure 5 shows the KPIs identified in this research.

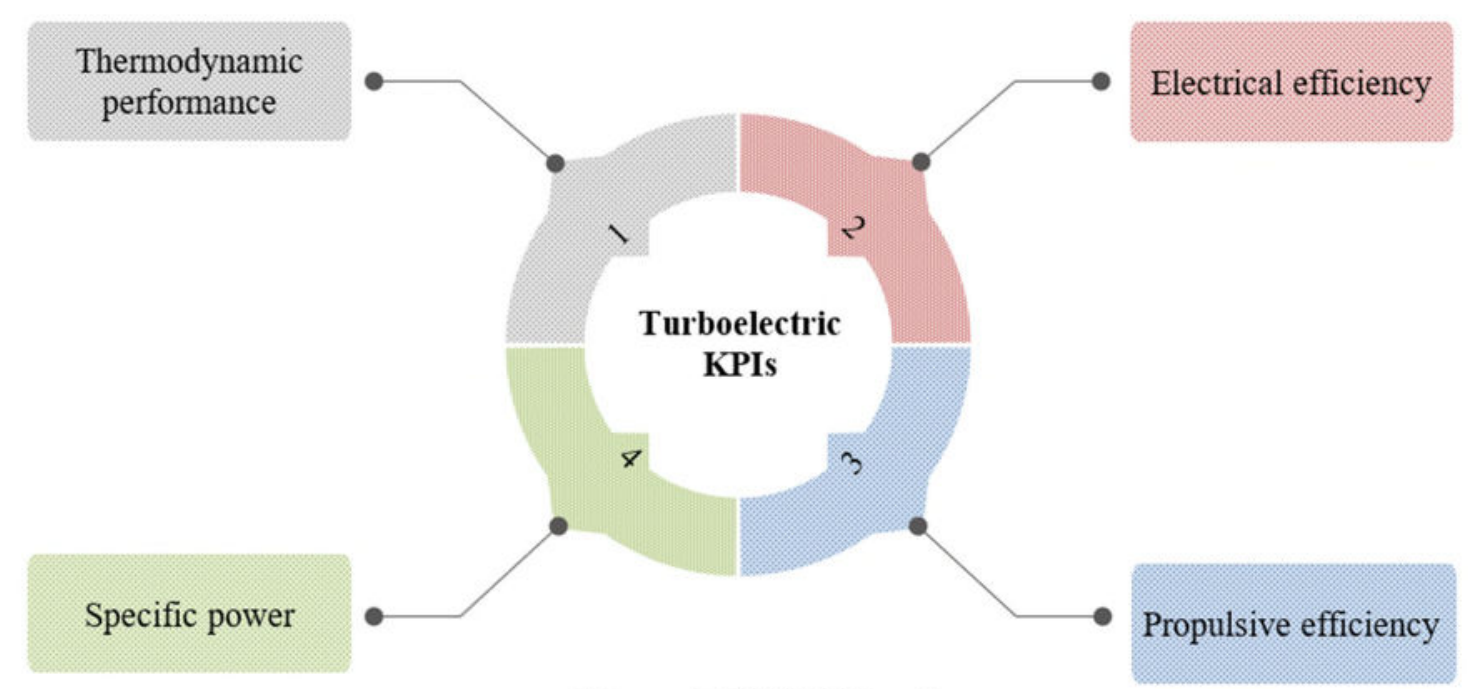

Figure 5: TeDP KPI cycle 
The KPI cycle defined in this study is a function of the electrical efficiency, propulsive efficiency, thermodynamic performance, and specific electrical drive power. These KPIs directly affect the weight of the system powertrain. Therefore, it is essential to select a powertrain that ensures maximum electrical power, particularly during take-off.

\section{Quantitative measurements}

Measurements of the identified KPIs should be recorded to quantify the improvements required to enable widespread application of TeDP systems in aircrafts. Data describing TeDP systems were collected from available published sources and simulated as a model using the Cranfield University in-house software TurboMatch. The case study model used for these quantitative measurements was a Cranfield TeDP named 'CTeDP-3'. This model was inspired by the joint development of the E-thrust concept by Airbus Group Innovations, Rolls Royce, and Cranfield University (Rolls Royce, 2012). It consists of two turboshaft engines (35 MW per engine), four electric generators (16 MW per generator), and 16 motor fans (4 MW per motor). The structure of the CTeDP-3 case study model is illustrated in Figure 6.

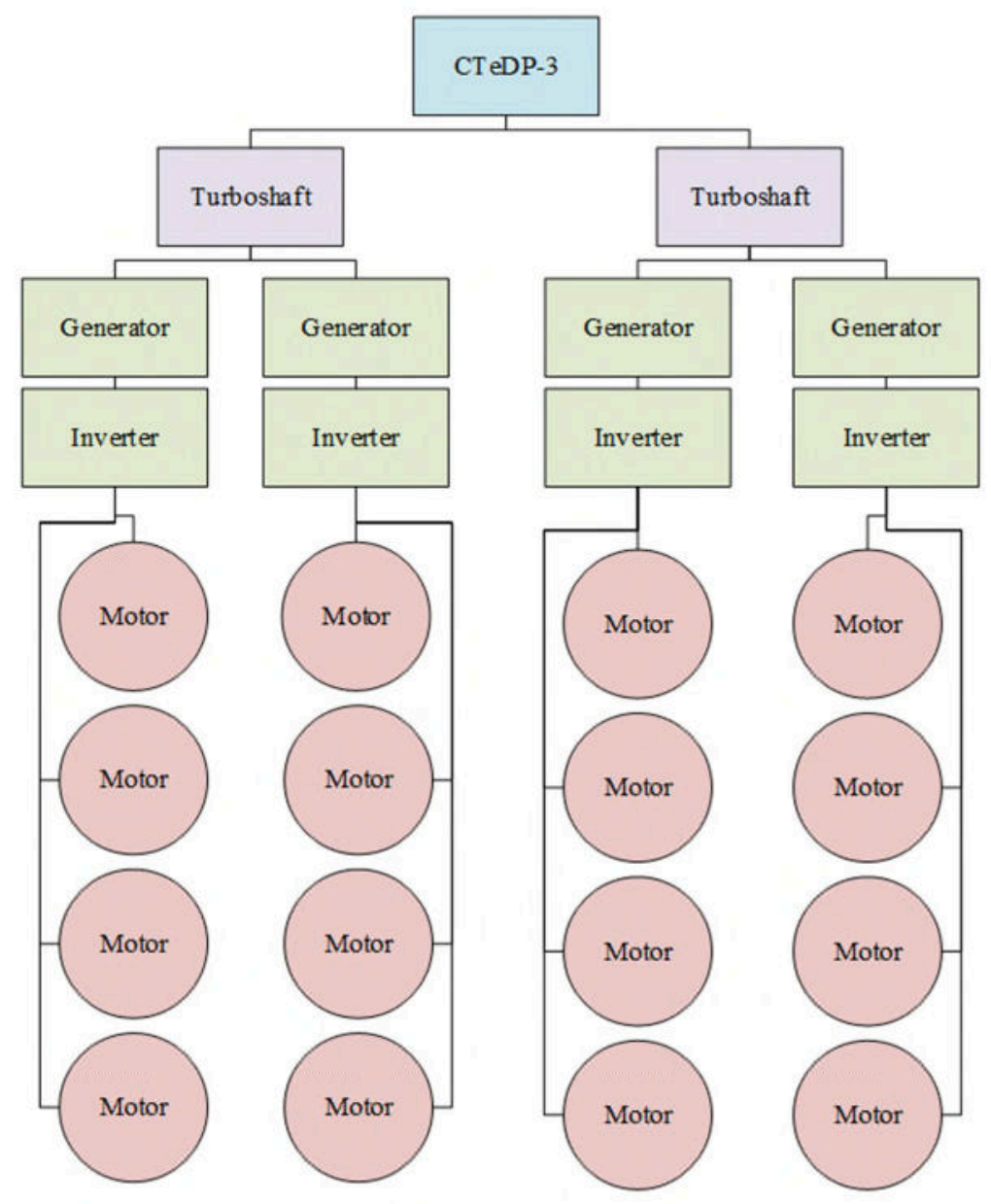

Figure 6: $\mathrm{CTeDP}-3$ case study model structure 
To study the thermodynamic performance KPI, the simulation involved the assumption that the turbofans were fuelled by hydrogen, with one spool, and operated off-design. Moreover, it was assumed the power required from each turbofan was $32 \mathrm{MW}$ for the two generators and the remaining $3 \mathrm{MW}$ for aircraft electricity. The engine characteristics were defined as follows: a net thrust of $43515.08 \mathrm{~N} / \mathrm{kg} / \mathrm{s}$, a fuel flow of $0.8518 \mathrm{~kg} / \mathrm{s}$, a specific fuel consumption of $0.0243 \mathrm{~g} / \mathrm{MJ}$, and a specific shaft power of $269230.77 \mathrm{~W}$. The resulting thermodynamic performance of the turboshaft is summarised in Table 1 and plotted in Figure 7.

Table 1

Turboshaft thermodynamic performance case study results.

\begin{tabular}{lccc}
\hline \multicolumn{1}{c}{ Station } & Mass flow $(\mathrm{kg} / \mathrm{s})$ & Total pressure $(\mathrm{atm})$ & Total temperature $(\mathrm{K})$ \\
\hline Intake & 130.0 & 1.0 & 288.15 \\
Compressor & 130.0 & 0.99 & 288.15 \\
Burner & 130.0 & 24.75 & 778.61 \\
Turbine & 130.852 & 23.51 & 1400.00 \\
Nozon & 130.852 & 1.28 & 761.01 \\
Performance & 130.852 & 1.28 & 761.01 \\
\hline
\end{tabular}

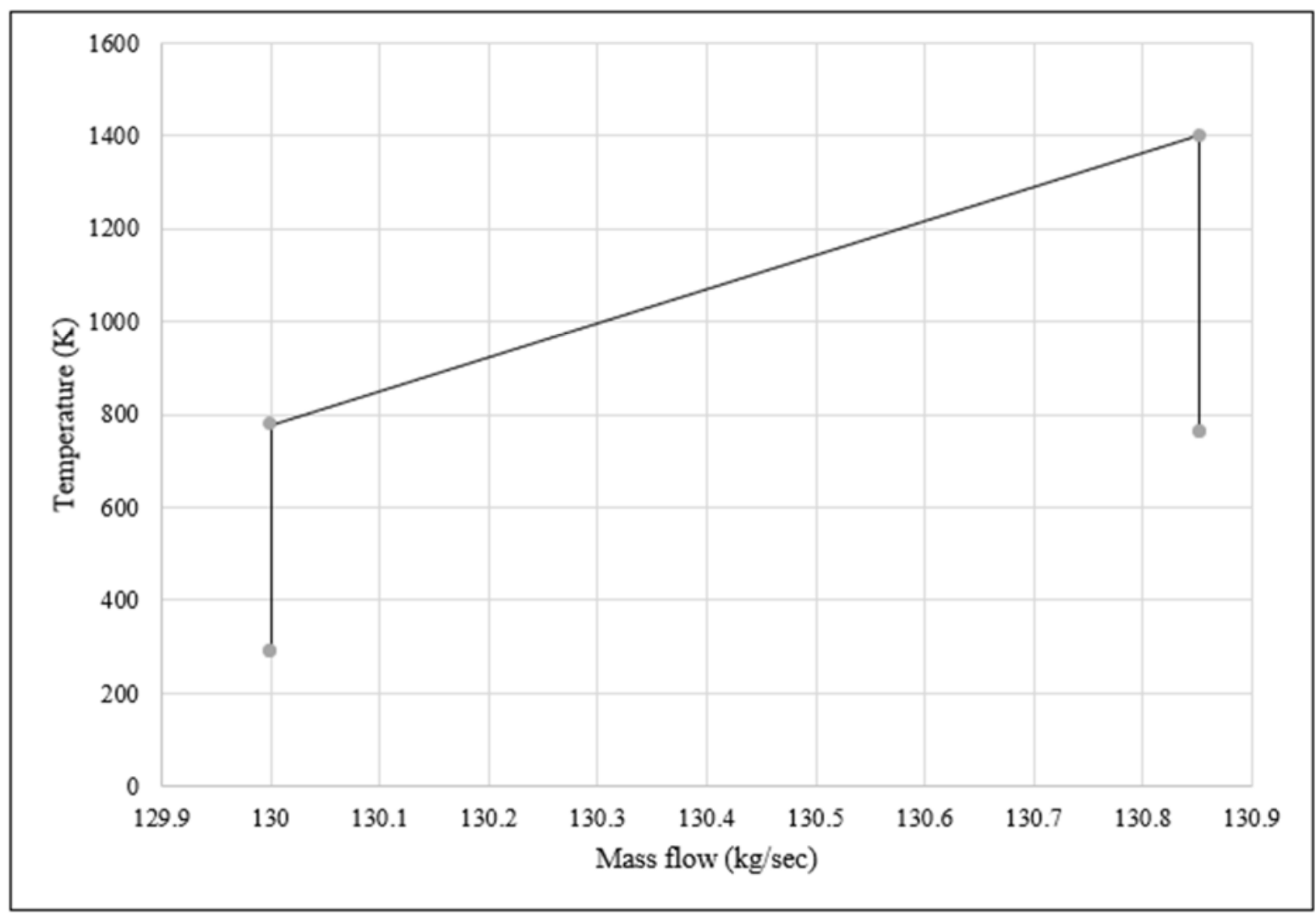

Figure 7: Turboshaft thermodynamic performance 
To study the electrical efficiency KPI, quantitative measurements of the efficiency of each component of the electrical grid were collected from the model. The assumptions presented in Table 2 were made for each component based on previously published calculated values (Felder et al., 2009a).

Table 2

Electrical efficiency case study results

\begin{tabular}{|c|c|c|c|}
\hline \multirow{5}{*}{$\begin{array}{c}\text { CTeDP-3 } \\
\text { model }\end{array}$} & Component & Proposed efficiency & Measured efficiency \\
\hline & Electric generators & $99.7 \%$ & $98.8 \%$ \\
\hline & Inverters & $98.8 \%$ & $95.2 \%$ \\
\hline & Electric motors & $99.5 \%$ & $92.2 \%$ \\
\hline & $\begin{array}{l}\text { High-temperature } \\
\text { superconductors }\end{array}$ & $99.0 \%$ & $99.0 \%$ \\
\hline \multicolumn{3}{|c|}{ Total electrical grid efficiency } & $85.85 \%$ \\
\hline
\end{tabular}

In this case study, propulsive efficiency was defined as the propulsive power delivered by the motors divided by the shaft power input to the propulsor (National Academies of Sciences, 2016). The specific power efficiency was assumed to be equal to the thermal efficiency. The resulting measurements from the CTeDP-3 case study model, along with the projected performance of each KPI, are accordingly presented in Table 3, where the target efficiency is defined as the highest efficiency could be found in the literature.

Table 3

Quantitative KPI results for CteDP-3 case study model

\begin{tabular}{|c|c|c|}
\hline KPI & Measured efficiency & Projected target efficiency \\
\hline Thermodynamic performance & $34.23 \%$ & $39.2 \%$ \\
\hline Electrical efficiency & $85.85 \%$ & $93.8 \%$ \\
\hline Propulsive efficiency & $91.42 \%$ & $94.4 \%$ \\
\hline Specific power & $34.23 \%$ & $39.2 \%$ \\
\hline Total TeDP system & $26.86 \%$ & $34.7 \%$ \\
\hline
\end{tabular}

\section{Results, discussion, and directions for future research}

The outcome of this study could be used to evaluate the KPIs and analyse the TeDP performance target, specified as the highest efficiency that could be found in the literature. The results from the TeDP model indicate that the lowest level of efficiency is associated with the 
thermodynamic performance KPI. This is because the standard gas turbine efficiency is 30 $40 \%$. Increasing this efficiency requires modification of the gas turbine design or model. Note that the thermodynamic efficiency was observed to decrease by $1.31 \%$ when changing the fuel from kerosene to hydrogen (for brevity, the results for kerosene are not included in this paper). Moreover, the specific power efficiency was assumed to be the same as the thermodynamic efficiency.

The electrical efficiency KPI had a calculated value of $85.85 \%$. Electrical efficiency is indeed generally higher than mechanical efficiency; however, the integration of mechatronic components can result in a reduction in the electrical efficiency. Furthermore, the implementation of multiple motors and generators within the system also results in a reduction in efficiency.

The propulsive efficiency KPI in the TeDP model was high as losses were mitigated by the integration of the electric propulsion system. Improving the propulsive efficiency is limited to changes in the design and propulsive distribution. Only the effect of mass flow on the total efficiency could additionally be accounted for, and this effect was neglected as it would have negligible impact on the results.

Figure 8 illustrates each KPI determined for the TeDP model and the corresponding error margin when compared with its target. It was found that improving the specific power or thermodynamic efficiency could improve the total system power by $3.9 \%$. In turn, this would positively affect the electric efficiency as the power could distributed better throughout the electric grid with a stable voltage, high electric current, and fewer elements in the system. However, the electrical efficiency enhancement was found to increase system power by $2.4 \%$. This would improve propulsion efficiency and specific power as well. These improvements account for a total increase in system power of around $8 \%$, which would, in turn, be reflected in improved economic and environmental performance, thereby validating the KPI cycle.

The findings of this study indicate the need to study the electrical grid of TeDP systems further and investigate opportunities to reduce the number of electric components incorporated in such systems to increase efficiency. The need to develop and model a gas turbine engine specifically for TeDP to achieve higher efficiency is also apparent. The results of this study suggest that implementing a TeDP system for aircraft in the short term requires a focus on thermodynamic efficiency as the primary KPI. This will improve the appeal of updating propulsion systems from legacy systems. However, in this study, it was found that the use of hydrogen fuel reduced 
the efficiency of the system compared with that achieved using kerosene. Note that fuel was not specifically considered a KPI because fuel and mass flow are captured as part of the thermodynamic and specific power KPIs.

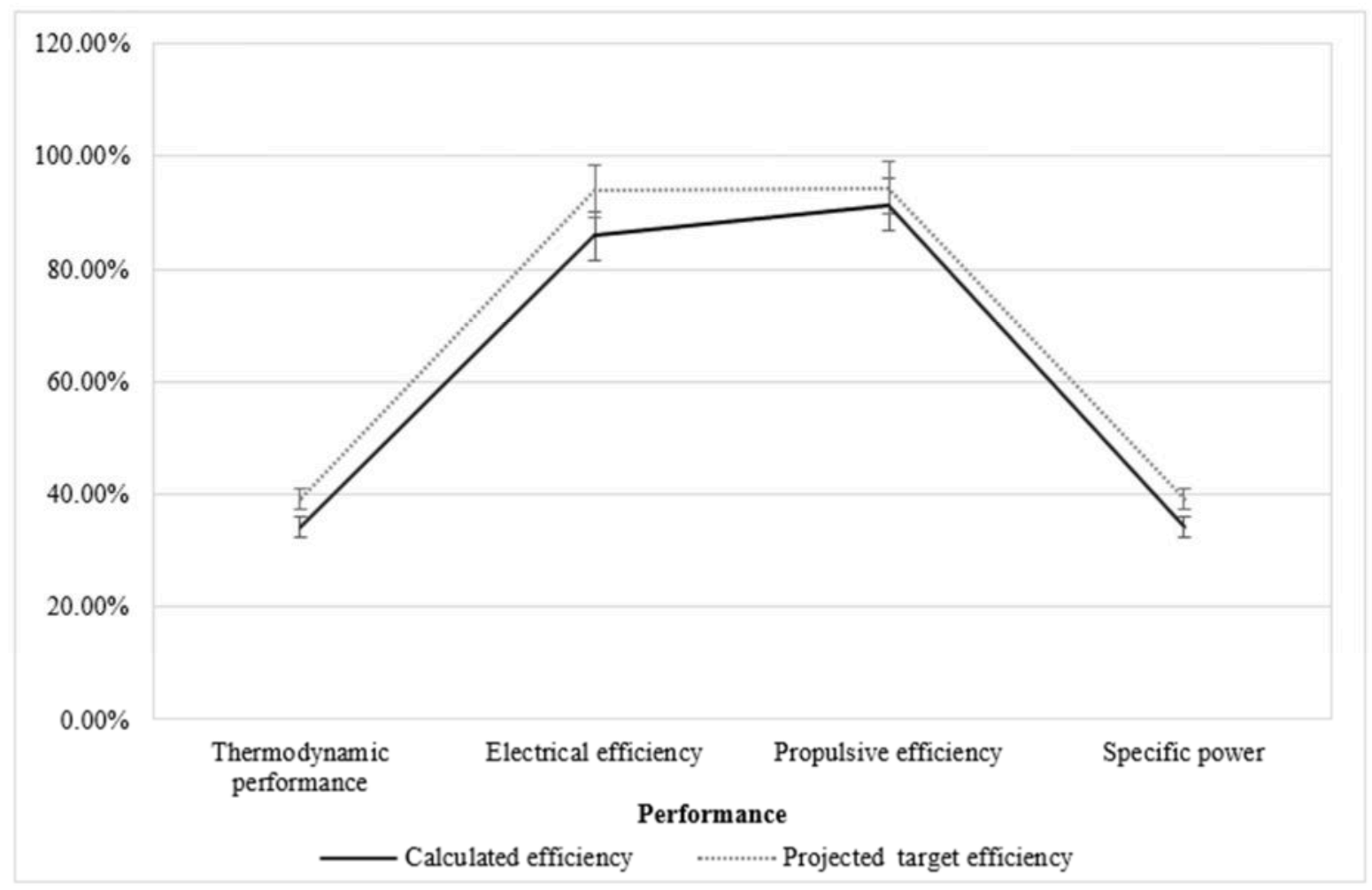

Figure 8: Turboelectric performance indicators

Figure 9 depicts each identified KPI and the respective percentage of the required improvement to meet the desired level of performance. The thermodynamic performance exhibits the most significant need for improvement (when combined with specific power), accounting for $48 \%$ of potential enhancement, and should thus receive the most attention in research and development. Electrical efficiency has received the least attention in TeDP improvement, but the importance of enhancing the electrical efficiency of generators and motors should not be neglected, as this KPI also accounts for a considerable portion (38\%) of the required improvement. 


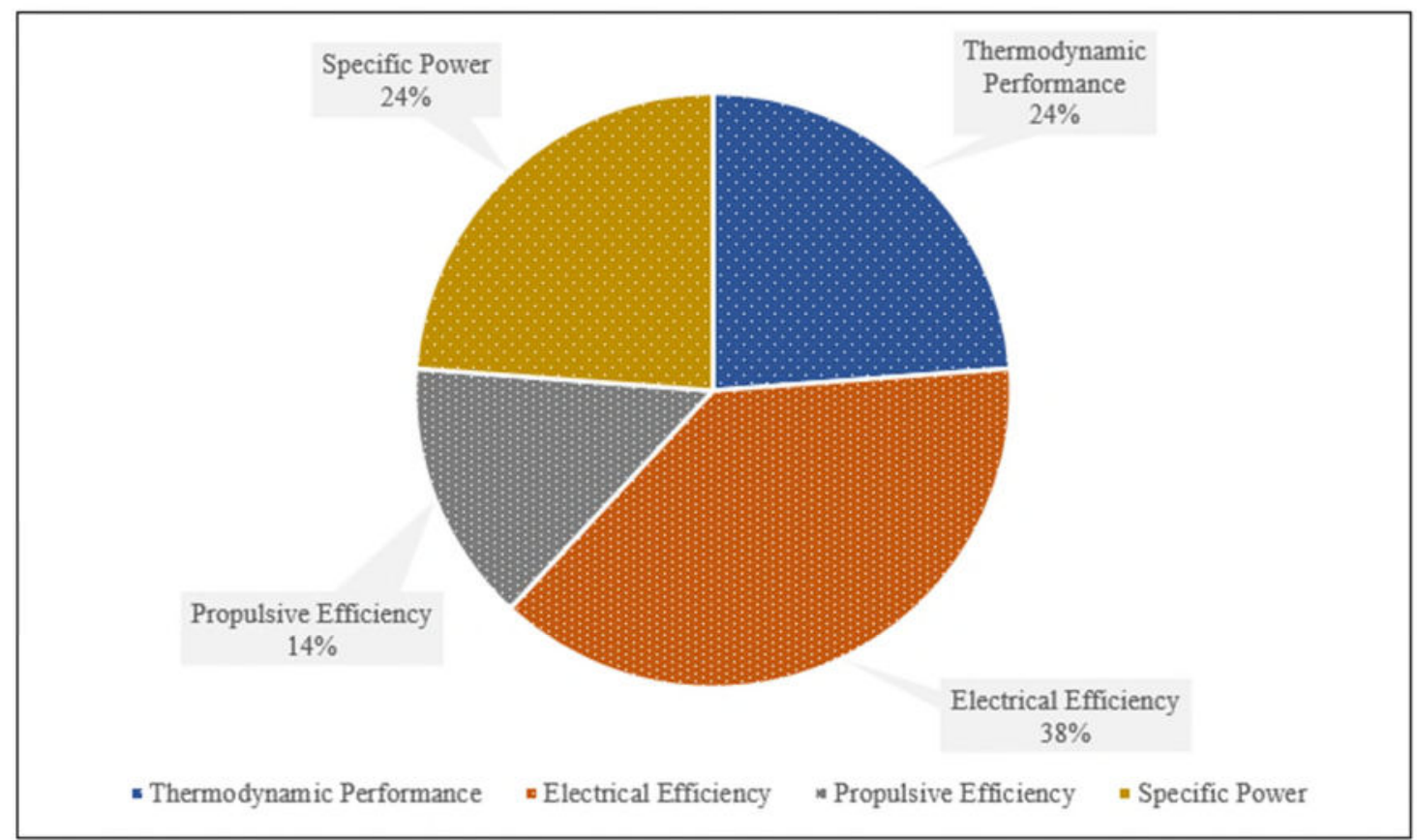

Figure 9: Performance enhancement of TeDP system for each performance indicator

A limitation of this study is that it evaluates only one type of gas turbine engine and one system model. Future studies should consider different types of fuel in addition to hydrogen and kerosene. Future research should also focus on the integration of the gearbox in the TeDP model and on the development of an alternative model to represent the electrical parts to improve the specific power and propulsion efficiency. Moreover, an improved model considering the weight ratio would be of tangible benefit in reducing wobble.

\section{Conclusions}

The objective of this study was to investigate the indicators that determine the performance of a TeDP system. The RIs of an aircraft using a TeDP system include reduced fuel/energy consumption, compliance with the requirements of certification agencies, reduced carbon emissions, reduced core weight, increased system component durability and sustainability, increased fuel availability and prices, and increased relative economic value. The PIs identified include system efficiency, carbon emissions, cooling requirements, power-to-weight ratio, high-temperature capabilities, and economic competitiveness. From these broad categories, the KRIs were identified as reliability, redundancy, independent power, and speed control, and the KPIs were determined to be thermodynamic performance, electrical efficiency, propulsive efficiency, and specific power. 
Improving the KPIs of a TeDP as determined via the TERA conducted in this study could increase the total efficiency of real-world TeDP systems by as much as $8 \%$. This enhancement will not only improve the technical performance of the propulsion system but also alter the economic and environmental attitudes towards adopting TeDP technology.

\section{References}

Adams, C.A. and Frost, G.R. (2008), "Integrating sustainability reporting into management practices", Accounting Forum, No longer published by Elsevier, Vol. 32 No. 4, pp. 288302.

AlNuaimi, B.K., Al Mazrouei, M. and Jabeen, F. (2020), "Enablers of green business process management in the oil and gas sector", International Journal of Productivity and Performance Management, Emerald Group Publishing Ltd., available at:https://doi.org/10.1108/IJPPM-11-2019-0524.

Alrashed, M., Nikolaidis, T., Pilidis, P., Alrashed, W. and Jafari, S. (2020), "Economic and environmental viability assessment of NASA's turboelectric distribution propulsion", Energy Reports, Elsevier Ltd, Vol. 6, pp. 1685-1695.

Alrashed, M., Nikolaidis, T., Pilidis, P. and Jafari, S. (2020), "Turboelectric Uncertainty Quantification and Error Estimation in Numerical Modelling", Applied Sciences, Multidisciplinary Digital Publishing Institute, Vol. 10 No. 5, p. 1805.

Armstrong, M., Ross, C., Phillips, D. and Blackwelder, M. (2013), "Stability, transient response, control, and safety of a high-power electric grid for turboelectric propulsion of aircraft", No. June, p. CR-2013-217865.

Armstrong, M.J., Ross, C.A.H., Blackwelder, M.J. and Rajashekara, K. (2012), "Propulsion System Component Considerations for NASA N3-X Turboelectric Distributed Propulsion System", SAE International Journal of Aerospace, Vol. 5 No. 2, pp. 344 353.

Bann, S.J., Malina, R., Staples, M.D., Suresh, P., Pearlson, M., Tyner, W.E., Hileman, J.I., et al. (2017), "The costs of production of alternative jet fuel: A harmonised stochastic assessment", Bioresource Technology, Elsevier Ltd, Vol. 227, pp. 179-187.

Brelje, B.J. and Martins, J.R.R.A. (2019a), "Electric, hybrid, and turboelectric fixed-wing aircraft: A review of concepts, models, and design approaches", Progress in Aerospace Sciences, Vol. 104, pp. 1-19.

Brelje, B.J. and Martins, J.R.R.A. (2019b), "Electric, hybrid, and turboelectric fixed-wing aircraft: A review of concepts, models, and design approaches", Progress in Aerospace Sciences, Elsevier Ltd, Vol. 104 No. August 2018, pp. 1-19.

Brown, G. V. (2011a), "Weights and efficiencies of electric components of a turboelectric aircraft propulsion system", 49th AIAA Aerospace Sciences Meeting Including the New Horizons Forum and Aerospace Exposition, American Institute of Aeronautics and Astronautics, Reston, Virigina, No. January, available at:https://doi.org/10.2514/6.2011225. 
Brown, G. V. (2011b), "Weights and efficiencies of electric components of a turboelectric aircraft propulsion system", 49th AIAA Aerospace Sciences Meeting Including the New Horizons Forum and Aerospace Exposition, available at:https://doi.org/10.2514/6.2011225.

Carre, F., Proust, E. and Schwartz, J. (1985), "Liquid metal versus gas cooled reactor concepts for a turbo electric powered space vehicle", available at: https://inis.iaea.org/search/search.aspx?orig_q=RN:16081484 (accessed 2 December 2019).

Chapman, J.W. (2019), "Multi-point design and optimisation of a turboshaft engine for a tiltwing turboelectric vtol air taxi”, AIAA Scitech 2019 Forum, available at:https://doi.org/10.2514/6.2019-1948.

Choi, B.B., Morrison, C., Dever, T. and Brown, G. V. (2014), "Propulsion electric grid simulator (PEGS) for future turboelectric distributed propulsion aircraft", 12th International Energy Conversion Engineering Conference, IECEC 2014, pp. 1-8.

Clegg, B. (1999), Innovation Agenda, Creativity and Innovation for Managers, Vol. 1, available at:https://doi.org/10.1016/b978-0-7506-4255-2.50012-5.

Dae Kim, H., Felder, J.L., Tong, M.T., Berton, J.J. and Haller, W.J. (2014), “Turboelectric distributed propulsion benefits on the N3-X vehicle", edited by Singh, R.Aircraft Engineering and Aerospace Technology, Emerald Group Publishing Limited, Vol. 86 No. 6, pp. 558-561.

Daffey, K. (Rolls-oRyce). (2014), "P\&E Panel: a Future With Hybrid Electric Propulsion Systems", Turbine Engine Technology Symposium, pp. 1-42.

Darecki, M., Edelstenne, C., Enders, T., Fernandez, E., Hartman, P., Herteman, J.-P., Kerkloh, M., et al. (2011), "Flightpath 2050", Flightpath 2050 Europe's Vision for Aviation, Publications Office, p. 28.

Davies, K., Norman, P., Jones, C., Galloway, S. and Burt, G. (2014), "Modelling the fault behaviour of a superconducting turboelectric distributed propulsion network", $S A E$ Technical Papers, Vol. 2014-Septe, available at:https://doi.org/10.4271/2014-01-2142.

Davies, K., Norman, P., Jones, C., Galloway, S. and Husband, M. (2013), “A review of Turboelectric Distributed Propulsion technologies for N+3 aircraft electrical systems", Proceedings of the Universities Power Engineering Conference, IEEE, pp. 1-5.

DiNovo, S. (1978), Preliminary Environmental Assessment of Biomass Conversion to Synthetic Fuels, National Service Center for Environmental Publications (NSCEP), Cincinnati, $\mathrm{OH} 45268$, available at: https://nepis.epa.gov/Exe/ZyPURL.cgi?Dockey=9101DL8Y.tx (accessed 2 December 2019).

Doulgeris, G., Korakianitis, T., Pilidis, P. and Tsoudis, E. (2012), "Techno-economic and environmental risk analysis for advanced marine propulsion systems", Applied Energy, Elsevier Ltd, Vol. 99, pp. 1-12.

Dryer, J. (2014), "Low Carbon Propulsion Strategic Thrust Overview", available at: https://ntrs.nasa.gov/search.jsp?R=20140010743 (accessed 2 December 2019).

English, R.E., Slone, H.O., Bernatowicz, D.T., Davison, E.H. and Lieblein, S. (1959), “A 20,000-kilowatt nuclear turboelectric power supply for manned space vehicles", 
available at: https://ntrs.nasa.gov/search.jsp?R=19980232007 (accessed 2 December 2019).

Esker, B. (2018), "Electric Aircraft Technology Development Overview Briefing", available at: https://ntrs.nasa.gov/search.jsp?R=20180006711 (accessed 2 December 2019).

Felder, J.L. (2014), "NASA N3-X with Turboelectric Distributed Propulsion”, IMechE Disruptive Green Propulsion Technologies Conference, p. 18.

Felder, J.L., Brown, G. V, Kim, H.D. and Chu, J. (2011), Turboelectric Distributed Propulsion in a Hybrid Wing Body Aircraft, available at: https://ntrs.nasa.gov/search.jsp?R=20120000856 (accessed 8 April 2020).

Felder, J.L., Kim, H.D. and Brown, G. V. (2009a), "Turboelectric distributed propulsion engine cycle analysis for hybrid-wing-body aircraft", 47th AIAA Aerospace Sciences Meeting Including the New Horizons Forum and Aerospace Exposition, American Institute of Aeronautics and Astronautics, Reston, Virigina, No. January, pp. 1-25.

Felder, J.L., Kim, H.D. and Brown, G. V. (2009b), "Turboelectric distributed propulsion engine cycle analysis for hybrid-wing-body aircraft", 47th AIAA Aerospace Sciences Meeting Including the New Horizons Forum and Aerospace Exposition, available at:https://doi.org/10.2514/6.2009-1132.

Felder, J.L., Kim, H.D., Brown, G. V. and Chu, J. (2011), “An examination of the effect of boundary layer ingestion on turboelectric distributed propulsion systems", 49th AIAA Aerospace Sciences Meeting Including the New Horizons Forum and Aerospace Exposition, American Institute of Aeronautics and Astronautics, Reston, Virigina, No. January, pp. 1-26.

Gargalo, C.L., Carvalho, A., Gernaey, K. V. and Sin, G. (2016), “A framework for technoeconomic \& environmental sustainability analysis by risk assessment for conceptual process evaluation", Biochemical Engineering Journal, Elsevier, Vol. 116, pp. 146-156.

Goldberg, C. (2017), “Techno-economic, environment and risk analysis of an aircraft concept with turboelectric distributed propulsion", available at:

https://dspace.lib.cranfield.ac.uk/handle/1826/14377 (accessed 2 December 2019).

Goldberg, C., Nalianda, D., Pilidis, P. and Singh, R. (2017), "Economic viability assessment of NASA's blended wing body N3-X aircraft", 53rd AIAA/SAE/ASEE Joint Propulsion Conference, 2017, No. July, pp. 1-16.

Graham, W.R., Hall, C.A. and Vera Morales, M. (2014), “The potential of future aircraft technology for noise and pollutant emissions reduction", Transport Policy, Elsevier, Vol. 34 No. 2014, pp. 36-51.

Graver, B., Zhang, K. and Rutherford, D. (2019), "CO2 emissions from commercial aviation, 2018”, No. September, p. 13.

Halachmi, A. (2011), "Imagined promises versus real challenges to public performance management", International Journal of Productivity and Performance Management, Emerald Group Publishing Limited, Vol. 60 No. 1, pp. 24-40.

Hofer, R. (2012), "Electric propulsion”, Aerospace America, Vol. 50 No. 11, p. 47.

IATA. (2016), "Jet fuel price development", Iata, available at: https://goo.gl/udgUDP (accessed 24 October 2019). 
ICAO. (2013), ICAO Environmental Report 2013, ICAO Environmental Report 2013, available at: http://www.icao.int/environmental-protection/Pages/EnvReport13.aspx (accessed 11 November 2019).

Innovations, A.G. (2012), E-ThRUST Electrical Distributed Propulsion System Concept.

Irfani, D.P., Wibisono, D. and Basri, M.H. (2019), "Integrating performance measurement, system dynamics, and problem-solving methods", International Journal of Productivity and Performance Management, Emerald Group Publishing Ltd., Vol. 69 No. 5, pp. 939961.

Ishak, Z., Fong, S.L. and Shin, S.C. (2019), "SMART KPI management system framework”, 2019 IEEE 9th International Conference on System Engineering and Technology, ICSET 2019 - Proceeding, Institute of Electrical and Electronics Engineers Inc., pp. $172-177$.

Jansen, R.H., Brown, G. V., Felder, J.L. and Duffy, K.P. (2015a), "Turboelectric aircraft drive key performance parameters and functional requirements", 51 st AIAA/SAE/ASEE Joint Propulsion Conference, American Institute of Aeronautics and Astronautics, Reston, Virginia, pp. 1-11.

Jansen, R.H., Brown, G. V., Felder, J.L. and Duffy, K.P. (2015b), “Turboelectric aircraft drive key performance parameters and functional requirements", 51st AIAA/SAE/ASEE Joint Propulsion Conference, American Institute of Aeronautics and Astronautics Inc, AIAA, available at:https://doi.org/10.2514/6.2015-3890.

Jansen, R.H., Duffy, K.P. and Brown, G. V. (2017a), "Partially turboelectric aircraft drive key performance parameters", 53rd AIAA/SAE/ASEE Joint Propulsion Conference, 2017, American Institute of Aeronautics and Astronautics Inc, AIAA, available at:https://doi.org/10.2514/6.2017-4702.

Jansen, R.H., Duffy, K.P. and Brown, G. V. (2017b), "Partially turboelectric aircraft drive key performance parameters", 53rd AIAA/SAE/ASEE Joint Propulsion Conference, 2017, American Institute of Aeronautics and Astronautics, Reston, Virginia, No. July, pp. $1-11$.

Kim, H.D., Brown, G. V. and Felder, J.L. (2008a), "Distributed Turboelectric Propulsion for Hybrid Wing Body Aircraft", 2008 International Powered Lift Conference, London,July, pp. 1-11.

Kim, H.D., Brown, G. V and Felder, J.L. (2008b), Distributed Turboelectric Propulsion for Hybrid Wing Body Aircraft, available at: https://ntrs.nasa.gov/search.jsp?R=20080021214 (accessed 8 April 2020).

Kim, H.D., Felder, J.L., Tong, M.T. and Armstrong, M.J. (2013), "Revolutionary Aeropropulsion Concept for Sustainable Aviation: Turboelectric Distributed Propulsion", 21st International Symposium on Air Breathing Engines (ISABE), pp. 1-12.

Kohlman, L. (2017), "Student Design Competition: Materials and Structures for Extreme Environments", available at: https://ntrs.nasa.gov/archive/nasa/casi.ntrs.nasa.gov/20170009382.pdf (accessed 2 December 2019).

Lee, D.S., Fahey, D.W., Forster, P.M., Newton, P.J., Wit, R.C.N., Lim, L.L., Owen, B., et al. (2009), "Aviation and global climate change in the 21st century", Atmospheric 
Environment, Elsevier Ltd, Vol. 43 No. 22-23, pp. 3520-3537.

Liu, C. (2013), “Turboelectric Distributed Propulsion System Modelling”, Dissertation at Cranfield University, No. December, pp. 2010-2013.

Liu, C., Doulgeris, G., Laskaridis, P. and Singh, R. (2013), "Thermal cycle analysis of turboelectric distributed propulsion system with boundary layer ingestion", Aerospace Science and Technology, Elsevier Masson SAS, Vol. 27 No. 1, pp. 163-170.

Liu, C., Si, X., Teng, J. and Ihiabe, D. (2016), "Method to Explore the Design Space of a Turbo-Electric Distributed Propulsion System", Journal of Aerospace Engineering, Vol. 29 No. 5, p. 04016027.

Łukasik, B. (2017), “Turboelectric distributed propulsion system as a future replacement for turbofan engines", Proceedings of the ASME Turbo Expo, American Society of Mechanical Engineers, Vol. 1, p. V001T01A017.

Lundgren, C., Bokrantz, J. and Skoogh, A. (2020), "Performance indicators for measuring the effects of Smart Maintenance", International Journal of Productivity and Performance Management, Emerald Group Publishing Ltd., available at:https://doi.org/10.1108/IJPPM-03-2019-0129.

Luongo, C.A., Masson, P.J., Nam, T., Mavris, D., Kim, H.D., Brown, G. V., Waters, M., et al. (2009), "Next generation more-electric aircraft: a potential application for hts superconductors", IEEE Transactions on Applied Superconductivity, Vol. 19 No. 3, pp. 1055-1068.

Manoochehri, G. (1999), "Overcoming obstacles to developing effective performance measures", Work Study, Emerald, Vol. 48 No. 6, pp. 223-229.

Masson, P.J., Ratelle, K., Delobel, P.A., Lipardi, A. and Lorin, C. (2013), "Development of a 3D sizing model for all-superconducting machines for turboelectric aircraft propulsion", IEEE Transactions on Applied Superconductivity, Vol. 23 No. 3, available at:https://doi.org/10.1109/TASC.2013.2239471.

Misra, A. (2018), “Technical Challenges and Barriers Affecting Turbo-electric and Hybrid Electric Aircraft Propulsion", Energytech, available at: https://ntrs.nasa.gov/search.jsp?R=20180004252 (accessed 2 December 2019).

Nalianda, D. and Singh, R. (2014), "Turbo-Electric distributed propulsion - Opportunities, benefits and challenges", edited by Singh, R.Aircraft Engineering and Aerospace Technology, Emerald Group Publishing Limited, Vol. 86 No. 6, pp. 543-549.

Nathan, A.J. and Scobell, A. (2012), "How China sees America", Foreign Affairs, Cranfield University, Montreal, Canada, Vol. 91 No. 5, pp. 1-86.

Oberly, C.E. (2006), "Lightweight superconducting generators for mobile military platforms", 2006 IEEE Power Engineering Society General Meeting, PES, IEEE, p. 8 pp.

Parmenter, D. (2010), Key Performance Indicator Developing, Implementing, and Using Winning KPIs. Second Edition, John Wiley \& Sons.

Propulsion, C.A., Engineering, S., Committee, B., Systems, E., Aviation, C., Emissions, C., Board, S.E., et al. (2016), Commercial Aircraft Propulsion and Energy Systems Research: Reducing Global Carbon Emissions, Commercial Aircraft Propulsion and 
Energy Systems Research: Reducing Global Carbon Emissions, National Academies Press, Washington, D.C., available at:https://doi.org/10.17226/23490.

Salyer, I.O. (2009), “Aircraft Using Turbo-Electric Hybrid Propulsion System”, 11 January, available at: https://patents.google.com/patent/US8727271B2/en (accessed 2 December 2019).

Schäfer, A.W., Evans, A.D., Reynolds, T.G. and Dray, L. (2016), "Costs of mitigating CO2 emissions from passenger aircraft", Nature Climate Change, Nature Publishing Group, Vol. 6 No. 4, pp. 412-417.

Schiltgen, B., Gibson, A.R., Green, M. and Freeman, J. (2013), "More electric aircraft: 'tube and wing' hybrid electric distributed propulsion with superconducting and conventional electric machines", SAE Technical Papers, Vol. 7, available at:https://doi.org/10.4271/2013-01-2306.

Schiltgen, B.T., Freeman, J.L. and Hall, D.W. (2016), “Aeropropulsive interaction and thermal system integration within the ECO-150: A turboelectric distributed propulsion airliner with conventional electric machines", 16th AIAA Aviation Technology, Integration, and Operations Conference, pp. 1-18.

Shahin, A. and Mahbod, M.A. (2007), "Prioritisation of key performance indicators: An integration of analytical hierarchy process and goal setting", International Journal of Productivity and Performance Management, Emerald Group Publishing Limited, Vol. 56 No. 3, pp. 226-240.

Shaw, J.C., Norman, P., Galloway, S. and Burt, G. (2014), "A Method for the Evaluation of the Effectiveness of Turboelectric Distributed Propulsion Power System Architectures", SAE International Journal of Aerospace, Vol. 7 No. 1, pp. 35-43.

Singh, A.K. and Sushil. (2013), "Modeling enablers of TQM to improve airline performance", International Journal of Productivity and Performance Management, Emerald Group Publishing Limited, March.

Stoll, A.M., Bevirt, J. Ben, Moore, M.D., Fredericks, W.J. and Borer, N.K. (2014), "Drag reduction through distributed electric propulsion", AIAA AVIATION 2014 -14th AIAA Aviation Technology, Integration, and Operations Conference, American Institute of Aeronautics and Astronautics, Reston, Virginia, No. June, pp. 16-20.

Tong, M.T., Halliwell, I. and Ghosn, L.J. (2004), “A computer code for gas turbine engine weight and disk life estimation", Journal of Engineering for Gas Turbines and Power, American Society of Mechanical Engineers Digital Collection, Vol. 126 No. 2, pp. 265270.

Uranga, A., Drela, M., Greitzer, E.M., Titchener, N.A., Lieu, M.K., Siu, N.M., Huang, A.C., et al. (2014), "Preliminary experimental assessment of the boundary layer ingestion benefit for the D8 aircraft", 52nd Aerospace Sciences Meeting, American Institute of Aeronautics and Astronautics, Reston, Virginia, No. January, pp. 1-27.

Verbano, C. and Crema, M. (2015), "Risk indicators for managing the energy procurement process", International Journal of Productivity and Performance Management, Emerald Group Publishing Ltd., Vol. 64 No. 2, pp. 228-242.

Wick, A.T., Hooker, J.R., Hardin, C.J. and Zeune, C.H. (2015), "Integrated aerodynamic benefits of distributed propulsion", 53rd AIAA Aerospace Sciences Meeting, American 
Institute of Aeronautics and Astronautics, Reston, Virginia, No. January, pp. 1-36.

Yazar, I. (2019), "Simulation of a High Fidelity Turboshaft Engine-Alternator Model for Turboelectric Propulsion System Design and Applications", International Journal of Turbo and Jet Engines, De Gruyter, Vol. 36 No. 3, pp. 271-281.

Zamboni, J., Vos, R., Emeneth, M. and Schneegans, A. (2019), A Method for the Conceptual Design of Hybrid Electric Aircraft, AIAA Scitech 2019 Forum, American Institute of Aeronautics and Astronautics, Reston, Virginia, 7 January, available at:https://doi.org/10.2514/6.2019-1587.

Zeng, Q., Beelaerts van Blokland, W., Santema, S. and Lodewijks, G. (2020), “A company performance index for motor vehicle manufacturers: company performance measurement with environmental concerns", International Journal of Productivity and Performance Management, Emerald Group Publishing Ltd., available at:https://doi.org/10.1108/IJPPM-08-2019-0393.

Zhao, W., Yu, H., Tian, L., Li, X. and Yan, G. (2017), "Nuclear power project performance management system research based on the KPIs", International Conference on Nuclear Engineering, Proceedings, ICONE, Vol. 1, American Society of Mechanical Engineers (ASME), available at:https://doi.org/10.1115/ICONE25-66073. 
$2021-02-23$

\title{
Key performance indicators for
}

\section{turboelectric distributed propulsion}

\author{
Alrashed, Mosab
}

Emerald

Alrashed M, Nikolaidis T, Pilidis P, et al., (2022) Key performance indicators for turboelectric distributed propulsion. International Journal of Productivity and Performance Management, Volume 71, Number 5, 2022, pp. 1989-2008

https://doi.org/10.1108/IJPPM-02-2020-0081

Downloaded from Cranfield Library Services E-Repository 